\title{
Endodontologie
}

\section{Perfekter Durchblick mit Kompass für Wurzelstifte}

Für jede Indikation den passenden Stift das Wurzelstiftsortiment von Komet ist riesig! Da ist es praktisch, schnell einen Kompass zur Hand zu haben, der klare Orientierung bietet. Der neue, kostenlose Kompass bringt als Leitlinie den Zerstörungsgrad eines Zahns mit der konkreten Indikation auf einen Punkt und empfiehlt daraus einen oder mehrere Wurzelstifte. ER-System, OptiPost, Vario oder BKS - zu allen Stiftsystemen werden auf den laminierten Seiten praktische Produkt- und Anwendungsempfehlungen gegeben. Auch an Revision und Aufbewahrung wurde gedacht. Wer die Stifte mit dem Composite-System DentinBuild Evo und DentinBond Evo einsetzen möchte, findet hierzu eine reich bebilderte Anleitung. Damit bietet der DIN A5-Kompass alles, was für das Setzen von Wurzelstiften vonnöten ist - auf einen Blick!

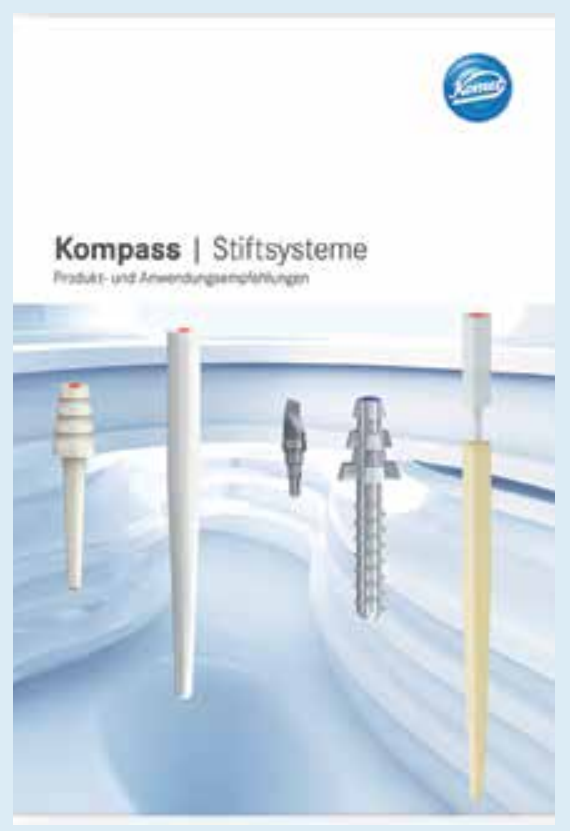

Nach einer Pressemitteilung der

Komet Dental Gebr. Brasseler GmbH \& Co KG,

Lemgo

Internet: www.kometdental.de 